\title{
Ursodeoxycholic acid and atorvastatin in the treatment of nonalcoholic steatohepatitis
}

\author{
Murat Kiyici MD¹, Macit Gulten MD¹, Selim Gurel MD¹, Selim Giray Nak MD¹, Enver Dolar MD², \\ Gursel Savci MD², Saduman Balaban Adim MD ${ }^{3}$, Omer Yerci MD $^{3}$, Faruk Memik MD ${ }^{1}$
}

\begin{abstract}
M Kiyici, M Gulten, S Gurel, et al. Ursodeoxycholic acid and atorvastatin in the treatment of nonalcoholic steatohepatitis. Can J Gastroenterol 2003;17(12):713-718.
\end{abstract}

BACKGROUND/AIMS: Nonalcoholic steatohepatitis (NASH) is a serious disorder with the potential to gradually progress to cirrhosis. It is generally associated with obesity, diabetes and hyperlipidemia. Currently, there is no established therapy for NASH. The aim of the present study was to evaluate the effectiveness of atorvastatin and ursodeoxycholic acid (UDCA) in the treatment of NASH.

METHODS: This prospective study included 44 adult patients (24 men, 20 women) with a mean age of $48.90 \pm 7.69$ years and mean body mass index (BMI) of $29.40 \pm 3.82$. Ten patients had a history of diabetes. Serological markers for viral hepatitis were negative in all patients and there was no history of alcohol or drug abuse. Patients who had autoimmune hepatitis were excluded from the study. Liver biopsy was performed before therapy to confirm the diagnosis. Among NASH patients, 17 normolipidemic cases received UDCA 13 to $15 \mathrm{mg} / \mathrm{kg} /$ day (group 1 ), while hyperlipidemic cases $(\mathrm{n}=27$ ) received atorvastatin $10 \mathrm{mg} /$ day (group 2) for six months. The BMI, serum lipids, liver function tests and liver density, assessed by computerized tomography, were evaluated before and after the treatment period. The BMI, serum aminotransferase levels, histological parameters (steatosis, inflammation, fibrosis scores) and liver densities were not statistically different between the groups at the beginning of therapy.

RESULTS: The BMI, serum glucose, and triglyceride levels did not change in either group after the treatment period. In group 1, serum alanine aminotransferase (ALT) and gamma-glutamyl-transferase (GGT) levels reduced significantly, and in group 2, serum cholesterol, aspartate aminotransferase, ALT, alkaline phosphatase and GGT levels reduced significantly. Liver densities increased only in group 2, probably as a result of diminishing fat content of liver. The normalization of transaminases was also more prevalent in group 2. Liver steatosis was closely correlated with liver density, but inflammation and fibrosis were not.

CONCLUSIONS: The use of atorvastatin in NASH patients with hyperlipidemia was found to be both effective and safe. The benefit of statin and UDCA therapy in normolipidemic patients with NASH requires confirmation with further placebo-controlled trials.

Key Words: Atorvastatin; Nonalcoholic steatohepatitis; Ursodeoxycholic acid

\section{L'acide ursodésoxycholique et l'atorvastatine dans le traitement de la stéatohépatite non alcoolique}

HISTORIQUE ET OBJECTIFS : La stéatohépatite non alcoolique (SHNA) est un trouble grave qui risque d'évoluer graduellement jusqu'à se transformer en cirrhose. D'ordinaire, elle s'associe à l'obésité, au diabète et à l'hyperlipidémie. Il n'existe aucun traitement établi contre la SHNA. La présente étude vise à évaluer l'efficacité de l'atorvastatine et de l'acide ursodésoxycholique (AUDC) dans le traitement de la SHNA. MÉTHODOLOGIE : La présente étude prospective portait sur 44 patients adultes (24 hommes, 20 femmes) à l'âge moyen de $48,90 \pm 7,69$ ans et à l'indice de masse corporelle (IMC) moyen de $29,40 \pm 3,82$. Dix patients avaient des antécédents de diabète. Les marqueurs sérologiques d'hépatite virale étaient négatifs chez tous les patients, et aucun ne présentait d'antécédents d'alcoolisme ou de toxicomanie. Les patients atteints d'hépatite chronique active autoimmune étaient exclus de l'étude. Une biopsie du foie a été effectuée avant le traitement afin de confirmer le diagnostic. Chez les patients atteints de SHNA, 17 cas normolipidémiques ont reçu de $13 \mathrm{mg} / \mathrm{kg} /$ jour à 15 $\mathrm{mg} / \mathrm{kg} /$ jour d'AUDC (groupe 1), tandis que les cas hyperlipidémiques $(\mathrm{n}=27)$ ont reçu $10 \mathrm{mg} /$ jour d'atorvastatine (groupe 2) pendant six mois. L'IMC, les lipides sériques, des tests de fonction hépatique et la densité hépatique, mesurée par tomodensitométrie, ont été évalués avant et après le traitement. L'IMC, les taux d'aminotransférase sérique, les paramètres histologiques (indices de stéatose, d'inflammation et de fibrose) et les densités hépatiques ne différaient pas d'un point de vue statistique entre les groupes au début du traitement.

RÉSULTATS : L'IMC, le glucose sérique et les taux de triglycérides n'avaient pas changé dans l'un ou l'autre groupe après le traitement. Dans le groupe 1, les taux d'alamine aminotransférase (ALT) sérique et de gamma-glutamyl-transférase (GGT) ont diminué de manière significative, et dans le groupe 2, les taux de cholestérol sérique, d'aspartate aminotransférase, d'ALT, de phosphatase alcaline et de GGT ont diminué de manière tout aussi significative. Les densités hépatiques augmentaient seulement dans le groupe 2, probablement par suite de la réduction de la teneur en matières grasses du foie. La normalisation des transaminases était également plus prévalente dans le groupe 2. Contrairement à l'inflammation et à la fibrose, la stéatose hépatique était étroitement reliée à la densité hépatique.

CONCLUSIONS : L'utilisation d'atorvastatine chez les patients atteints de SHNA souffrant aussi d'hyperlipidémie était à la fois sûre et efficace. Le bénéfice de la statine et de la thérapie à l'AUDC chez les patients normolipidémiques atteints de SHNA devra être confirmé par d'autres essais contre placebo.

${ }^{1}$ Department of Gastroenterology; ${ }^{2}$ Department of Radiology; and ${ }^{3}$ Department of Pathology, Uludag University Medical Faculty, Bursa, Turkey Correspondence: Dr Murat Kiyici, Department of Gastroenterology, Uludag University, Medical Faculty, 16059, Bursa, Turkey.

Telephone +90-224-442-8400 ext 1295, fax+90-224-442-8858, e-mail mkiyici@uludag.edu.tr

Received for publication April 24, 2003. Accepted September 22, 2003 
$\mathrm{N}$ onalcoholic steatohepatitis (NASH) is defined as microand macrovesicular type fatty infiltration of the liver, that is accompanied by lobular inflammation and mild to severe fibrosis in the absence of a history of alcohol abuse. This insidious and progressive disorder is particularly associated with obesity, type 2 diabetes (insulin resistance) (1), hyperlipidemia and some drugs. Although the pathophysiology is not clearly understood, insulin resistance and oxidative stress appear to be involved in the process. Generally, patients are asymptomatic and laboratory studies may only demonstrate a two- to three-fold increase in aminotransferase levels (2).

Imaging studies, such as ultrasound, computerized tomography (CT) and magnetic resonance imaging have all been shown to be useful for predicting and quantifying the severity of the process $(3,4)$. However, liver biopsy remains the gold standard for definitive diagnosis as well as for grading and staging of NASH (5).

Currently, there is no approved therapy for NASH. Weight reduction, abstaining from alcohol consumption, control of diabetes and hyperlipidemia, withdrawal of responsible drugs, ursodeoxycholic acid (UDCA) therapy, and phlebotomy to remove excess hepatic iron are all recommendations which have been shown to have beneficial effects (6). In particular, sustained weight loss and UDCA are thought to alter the course of NASH. There has been no published data on the use of hydroxymethylglutaryl coenzyme A reductase inhibitors in the management of NASH in the literature (6).

In this study, the effectiveness of atorvastatin, a cholesterollowering statin, and UDCA, a tertiary bile acid, in the treatment of NASH was compared.

\section{Patients}

\section{PATIENTS AND METHODS}

The prospective study included 44 patients with NASH. Informed consent was obtained from each patient. The patients in whom serum alanine aminotransferase (ALT) levels were elevated above normal range were accepted into the study. Whole viral and auto-immune hepatitis markers were negative in all patients. There was no history of alcohol abuse. A detailed drug history was undertaken to exclude patients receiving possible causative drugs. Liver biopsy was obtained in all cases to confirm the diagnosis of NASH before therapy and those with histologically proven cirrhosis were not included in the study. Liver biopsies were also examined and scored by two experienced pathologists for grading steatosis and inflammation and for staging fibrosis according to Brunt et al's (5) histological scoring system for NASH. The demographic, laboratory and histological data of the patients are summarized in Table 1 .

\section{Methods}

Patients were divided into two groups as follows: group $1(n=17)$ received UDCA 13 to $15 \mathrm{mg} / \mathrm{kg} /$ day and group $2(\mathrm{n}=27)$ received atorvastatin $10 \mathrm{mg} /$ day for six months. Patients with serum total cholesterol levels greater than $5.20 \mathrm{mmol} / \mathrm{L}$ were treated with atorvastatin due to its lipid-reducing effect. The body mass index (BMI), serum lipids, liver function tests and CT liver densities were recorded before and after the treatment period in both groups. To evaluate liver density, three operator-defined electronic regions of interest from three separate and homogeneous areas in both lobes of the liver on a noncontrast CT image were obtained by passing through the porta hepatis; during measurement a special effort was made to avoid focal lesions, vessels and beam-

\section{TABLE 1}

Characteristics of the patients in treatment groups

\begin{tabular}{|c|c|c|c|}
\hline & $\begin{array}{c}\text { Group 1 } \\
\text { (ursodeoxycholic acid) }(n=17)\end{array}$ & $\begin{array}{c}\text { Group 2 } \\
\text { (atorvastatin) }(n=27)\end{array}$ & $P$ value \\
\hline Age (years) & $43.7 \pm 1.8$ & $50.2 \pm 1.4$ & 0.008 \\
\hline Sex (male/female) & $12 / 5$ & $12 / 15$ & 0.082 \\
\hline Diabetes, n (\%) & $4(23 \%)$ & $6(22 \%)$ & 0.599 \\
\hline Body mass index & $28.7 \pm 0.8$ & $29.7 \pm 0.8$ & 0.398 \\
\hline Glucose (mmol/L) & $5.99 \pm 0.57$ & $5.71 \pm 0.20$ & 0.587 \\
\hline Cholesterol, total (mmol/L) & $4.42 \pm 0.24$ & $6.16 \pm 0.17$ & 0.0001 \\
\hline Triglyceride (mmol/L) & $2.02 \pm 0.31$ & $2.12 \pm 0.14$ & 0.754 \\
\hline Aspartate aminotransferase (U/L) & $47.5 \pm 5.0$ & $45.4 \pm 4.0$ & 0.759 \\
\hline Alanine aminotransferase (U/L) & $76.0 \pm 6.6$ & $81.8 \pm 8.9$ & 0.667 \\
\hline Alkaline phosphatase (U/L) & $89.6 \pm 8.9$ & $98.7 \pm 6.6$ & 0.429 \\
\hline Gamma-glutamyl-transferase (U/L) & $47.8 \pm 6.9$ & $64.2 \pm 9.5$ & 0.197 \\
\hline Bilirubin, total $(\mu \mathrm{mol} / \mathrm{L})$ & $11.97 \pm 1.02$ & $11.97 \pm 1.19$ & 0.813 \\
\hline Bilirubin, direct $(\mu \mathrm{mol} / \mathrm{L})$ & $5.13 \pm 0.68$ & $3.42 \pm 0.34$ & 0.323 \\
\hline Albumin ( $g / L)$ & $43 \pm 1.0$ & $4.5 \pm 0.08$ & 0.332 \\
\hline Globulin (g/L) & $29 \pm 2.0$ & $29 \pm 1.0$ & 0.945 \\
\hline Liver density (HU) & $40.6 \pm 3.8$ & $38.1 \pm 2.5$ & 0.570 \\
\hline Steatosis score* & $2.37 \pm 0.32$ & $2.00 \pm 0.57$ & 0.568 \\
\hline Inflammation score* & $2.12 \pm 0.22$ & $1.66 \pm 0.33$ & 0.309 \\
\hline Fibrosis score* & $1.62 \pm 0.49$ & $1.00 \pm 0.57$ & 0.488 \\
\hline Perisinusoidal fibrosis & $0.87 \pm 0.35$ & $0.33 \pm 0.33$ & 0.405 \\
\hline Portal fibrosis & $1.37 \pm 0.49$ & $0.66 \pm 0.33$ & 0.269 \\
\hline Bridging fibrosis & $0.41 \pm 015$ & $0.28 \pm 0.14$ & 0.087 \\
\hline
\end{tabular}

Data presented as mean \pm SEM. *Histological parameters scored by Brunt et al's (5) histological scoring system for nonalcoholic steatohepatitis 


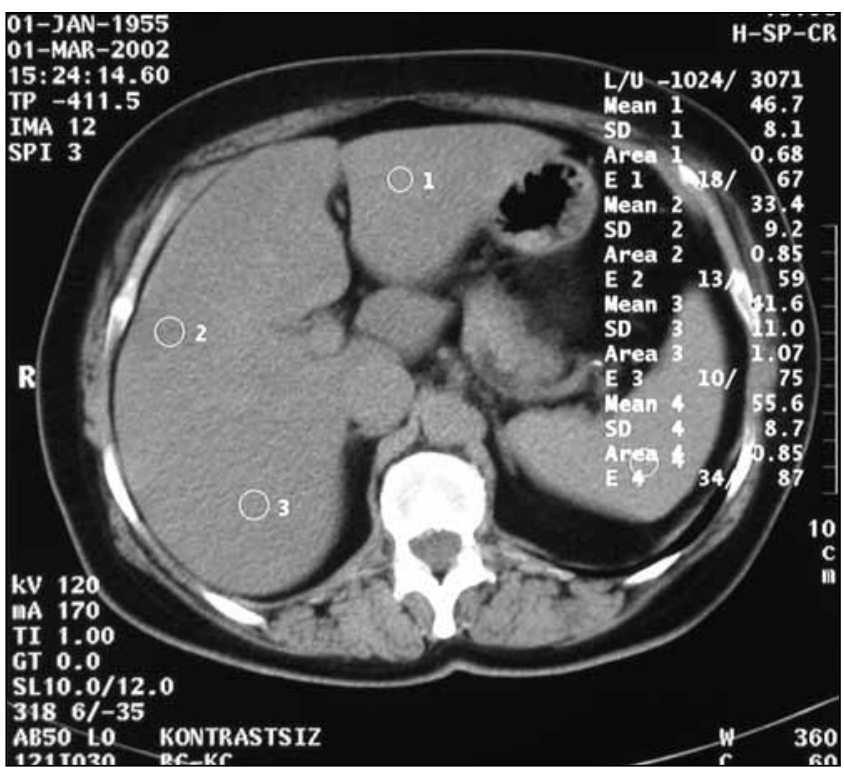

Figure 1) The measurements of liver density in noncontrast computerized tomography slice passing through the porta hepatis. The mean liver density measured by attenuation values from three different and homogeneous areas in both liver lobes. Focal lesions, vessels and beam hardening or streak artifacts were avoided

hardening or streak artifacts. The attenuation values from the three selected areas were averaged (Figure 1).

\section{Statistical analysis}

Results were given as mean \pm SEM. Student's $t$ test was used for analyzing differences, between variables, in groups. Fisher's exact test was used to compare other nominal parameters such as sex, presence of diabetes and normalization of transaminases between groups. $\mathrm{P}<0.05$ was considered statistically significant for all analyses. Data entry and statistical analyses were performed with SPSS for Windows (Version 11; SPSS Inc, USA).

\section{RESULTS}

At the beginning of the therapy, there was no difference between groups according to their BMI, glucose and triglyceride levels, transaminases, bilirubin, albumin and globulin levels. The groups were equal with respect to sex and presence of diabetes mellitus $(\mathrm{P}=0.082$ and $\mathrm{P}=0.599$, respectively). Patients in group 1 (UDCA) were younger than those in group $2(\mathrm{P}<0.05)$. The total cholesterol levels of patients receiving atorvastatin (group 2) were higher than levels in group $1(\mathrm{P}<0.05)$ as a result of patient selection. Liver densities of patients were not different between groups. The grade and stage of histological lesions were also similar and groups were comparable according to steatosis, inflammation and fibrosis scores (Table 1). Liver density levels were reversely correlated with liver steatosis scores $(\mathrm{P}<0.05)$ (Figure 2). However, inflammation and fibrosis scores were not related with liver densities ( $\mathrm{P}>0.05)$ (Figures 3 and 4 ).

The BMI, glucose and triglyceride levels did not change significantly in either group after the treatment period. In group 1, serum ALT and gamma-glutamyl-transferase (GGT) levels were significantly lower $(\mathrm{P}<0.02)$, but there was no change in cholesterol, aspartate aminotransferase (AST) and alkaline

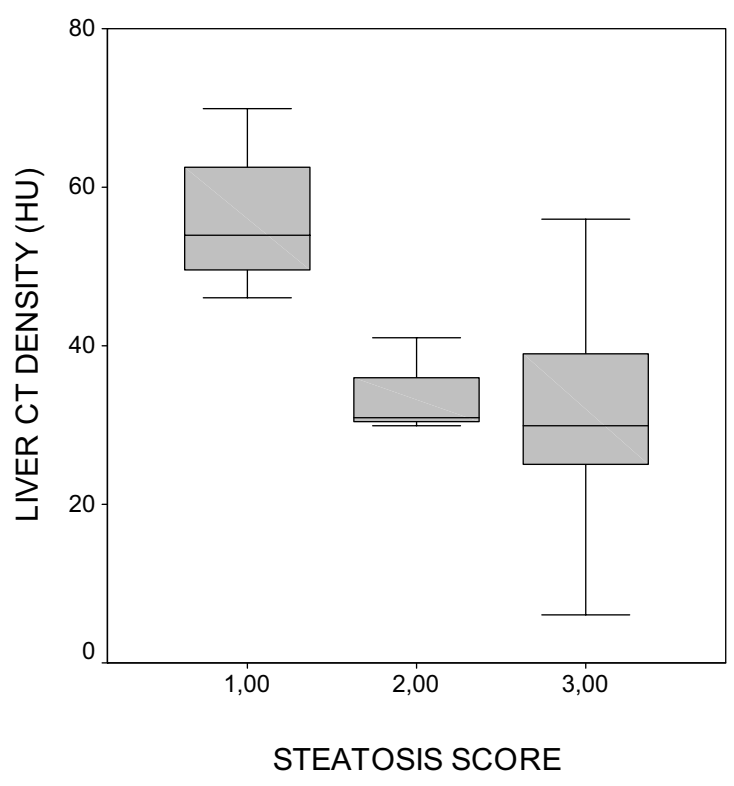

Figure 2) Relationship between steatosis and liver computerized tomography (CT) density. Macro- and microvesicular steatosis was graded between 0 and 3 points based on percentage of hepatocytes in the biopsy involved ( 0 is none; 1 is up to $33 \%$; 2 is $33 \%$ to $66 \%$; 3 is greater than 66\%) (5). As the liver steatosis increased, liver CT density decreased proportionally. There was a statistically significant difference between liver densities of patients with steatosis scores 1 and 2 $(P=0.021)$, and scores 1 and $3(P=0.07)$

phosphatase (ALP) levels. In group 2, more significant changes were observed. Cholesterol levels decreased as expected but AST, ALT, ALP and GGT levels had also reduced significantly $(\mathrm{P}<0.02)$ (Table 2$)$.

Although liver densities did not change following therapy in group $1(\mathrm{P}=0.083)$, there was a considerable increase in response to treatment $(\mathrm{P}=0.0001)$ in group 2 patients (Table 2$)$.

Although post-treatment AST levels were different in favour of group 2, statistical analyses on the percentage of variations of AST, ALT, BMI and liver density by the therapy (calculate as $100 \times$ [post-treatment value - pretreatment value]/ pretreatment value) did not reveal any significant alteration between groups $(\mathrm{P}>0.05)$ (Table 3$)$.

Finally, for the patients in whom transaminase values were normalized after the therapy, group 2 displayed clear improvement (16 of 27 patients) over group 1 (four of 17 patients) and this normalization was statistically significant $(\mathrm{P}=0.021)$.

\section{DISCUSSION}

Currently, there is no established therapy that alters the course of NASH. Day and James (7) proposed the "two hits hypothesis" (first hit: steatosis, second hit: oxidative stress and abnormal cytokine production) in the pathogenesis of NASH. Thus, it is logical to design drug therapies to counter the effects of first and/or second hits of this disease on the liver. Strict diets for weight reduction, antioxidant therapies such as vitamin $\mathrm{C}$ and vitamin $\mathrm{E}(8,9)$, control of diabetes and/or hyperlipidemia and UDCA treatment have also been tried to counter these effects. In a pilot study, Laurin et al (10) noted that one year of UDCA 


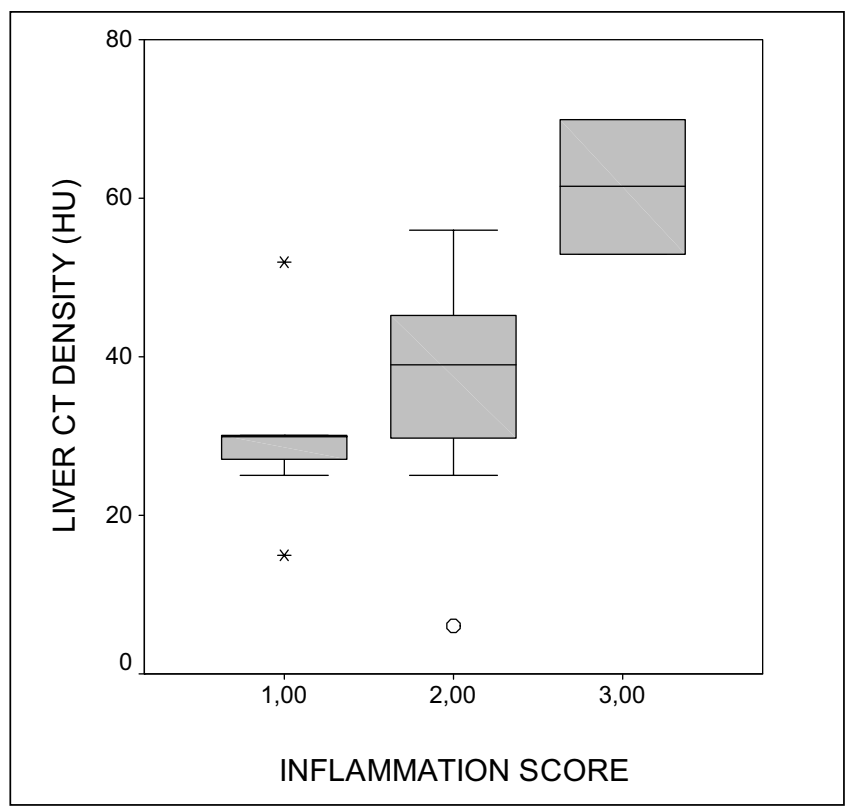

Figure 3) Relationship between inflammation and liver computerized tomography (CT) density. Necroinflammatory grade was graded from 0 to 4.0 is no inflammation; 1 (mild) is scattered intra-acinar inflammation consisting of small collections of polymorphonuclear leukocytes with or without lymphocytes, and no or mild portal chronic inflammation; 2 (moderate) is more noticeable intra-acinar inflammation and mild to moderate portal inflammation, and interface activity; 3 (severe) is increased lobular and portal inflammation compared with grade 2 (5). The authors could not demonstrate any statistically significant difference among liver densities of patients with low, moderate or high grade inflammatory activity $(P>0.05)$. Extremes: Cases with values more than three box lengths from the upper or lower edge of the box. The box length is the interquartile range. OOutliers: Cases with values between 1.5 and 3 box lenghts form the upper or lower edge of the box

therapy significantly improved serum ALT, ALP and GGT levels and grade of hepatic steatosis in NASH patients. However, they stated that the grade of inflammation and fibrosis did not change with this therapy, but that UDCA was effective in the treatment of NASH due to its cytoprotective property. In that study, Laurin et al (10) compared the effects of UDCA and clofibrate. They put hyperlipidemic patients into the clofibrate group as we did for atorvastatin group. It is appropriate to divide patients into groups according to their biochemical status rather than randomizing them, due to different drug effects. In this study, BMI and blood glucose levels of patients in the two groups showed no significant alteration after therapy so the results could not be attributed to any weight loss or regulation of patients' diabetes.

Although transaminase levels tended to decrease in the two groups, which was somewhat more evident in group 2, the percentages of variations showed no significant difference. It can therefore be concluded that these two drugs are equally effective in lowering elevated liver function tests. The small risk of hepatotoxicity with atorvastatin therapy, manifested as elevation of transaminases, was not observed in our study. Although there were minor transient elevations of transaminases in a minority of patients, not exceeding

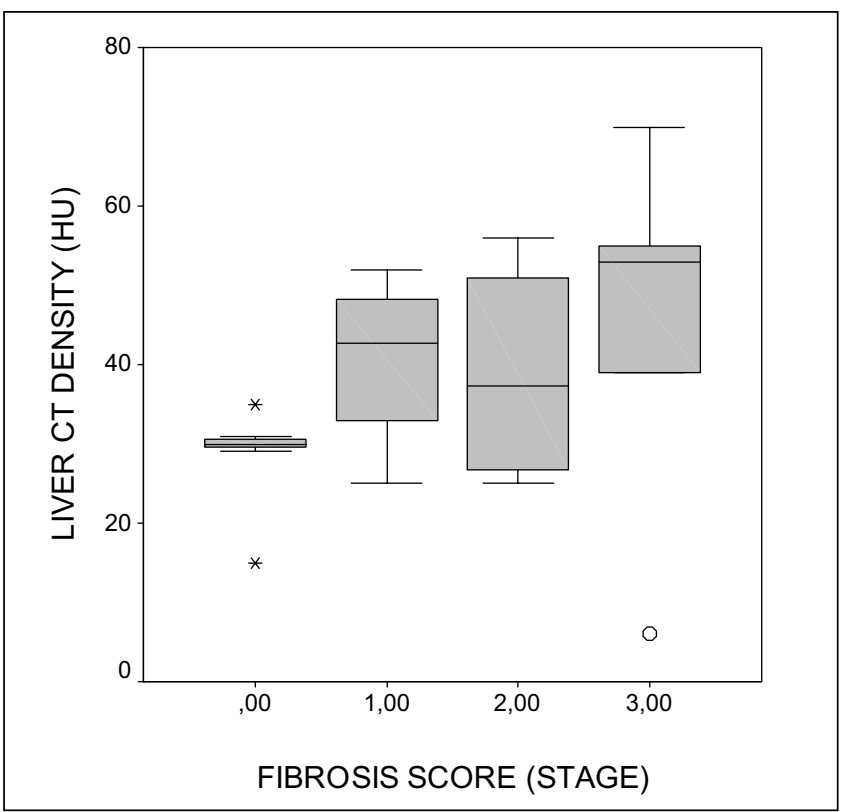

Figure 4) Relationship between fibrosis and liver computerized tomography (CT) density. Evaluation of fibrosis initially performed in three different areas in lobules. Perisinusoidal fibrosis was scored between 0 and 3 points on percentage of zone 3 foci involved ( 0 is none; 1 is up to $33 \% ; 2$ is $33 \%$ to $66 \% ; 3$ is greater than $66 \%)$. Portal fibrosis was scored between 0 and 4 points ( 0 is none; 1 is expanded portal tracts; 2 is periportal fibrosis; 3 is bridging fibrosis with nodular architecture; 4 is cirrhosis). Bridging fibrosis was scored between 0 and 4 ( 0 is none; 1 is one focus; 2 is more than one focus with no nodularity; 3 is bridging fibrosis with nodular remodelling; 4 is cirrhosis) (5). Furthermore, patients were graded into 0 to 4 stages depending on the patterns of fibrosis. Stage 1 is focal or extensive perisinusoidal fibrosis in zone 3; stage 2 is perisinusoidal fibrosis in zone 3 with focal or extensive periportal fibrosis; stage 3 is perisinusoidal fibrosis in zone 3 and portal fibrosis with focal or extensive bridging fibrosis; stage 4 is cirrhosis (5). As a result of patient selection, no patient with cirrhosis included in this study. Liver densities were not significantly different in patients with different stages of nonalcoholic steatohepatitis ( $P>0.05) *$ Extremes: Cases with values more than three box lengths from the upper or lower edge of the box. The box length is the interquartile range. OOutliers: Cases with values between 1.5 and 3 box lenghts form the upper or lower edge of the box

1.5 fold, they stabilized with continuation of the drug and no patient was obliged to drop out of the study because of this side effect. Rhabdomyolysis, an important side effect of statins, was not encountered in patients receiving atorvastatin.

Measuring liver density by noncontrast CT technique is a noninvasive and easy way to assess and follow up the fat content of liver. Other methods are abdominal ultrasonography, standard magnetic resonance imaging techniques (spin and gradient echo) and magnetic resonance spectroscopy (4). A diffusely echogenic pattern is observed in fatty liver in ultrasonography, but this method is not suitable for quantification of steatosis or for the detection of lesser degrees of fatty infiltration. Increased fat content within hepatocytes decreases the liver density, and qualitative liver density assessment can therefore be done by comparing it with spleen density. Arithmetic mean value of liver densities measured in three dif- 
TABLE 2

Parameters after treatment in both groups

\begin{tabular}{|c|c|c|c|c|c|}
\hline & \multicolumn{2}{|c|}{ Group 1 (ursodeoxycholic acid) } & \multicolumn{2}{|c|}{ Group 2 (atorvastatin) } & \multirow[b]{2}{*}{$P$ value } \\
\hline & Mean \pm SEM & P value* & Mean \pm SEM & $P$ value* & \\
\hline Body mass index & $29.2 \pm 1.1$ & 0.446 & $29.5 \pm 1.1$ & 0.440 & 0.846 \\
\hline Glucose (mmol/L) & $6.24 \pm 0.82$ & 0.669 & $5.42 \pm 0.17$ & 0.077 & 0.356 \\
\hline Cholesterol, total (mmol/L) & $4.57 \pm 0.34$ & 0.689 & $4.75 \pm 0.18$ & 0.0001 & 0.621 \\
\hline Triglyceride (mmol/L) & $1.89 \pm 0.20$ & 0.216 & $1.86 \pm 0.23$ & 0.194 & 0.935 \\
\hline Aspartate aminotransferase (U/L) & $43.7 \pm 4.3$ & 0.132 & $32.1 \pm 3.0$ & 0.004 & 0.033 \\
\hline Alanine aminotransferase (U/L) & $55.1 \pm 7.2$ & 0.002 & $44.8 \pm 5.7$ & 0.0001 & 0.286 \\
\hline Alkaline phosphatase (U/L) & $94.3 \pm 7.4$ & 0.672 & $109.0 \pm 7.1$ & 0.017 & 0.206 \\
\hline Gamma-glutamyl-transferase (U/L) & $32.2 \pm 3.0$ & 0.016 & $37.2 \pm 4.2$ & 0.014 & 0.349 \\
\hline Liver density (HU) & $44.7 \pm 4.3$ & 0.083 & $48.7 \pm 2.5$ & 0.0001 & 0.407 \\
\hline
\end{tabular}

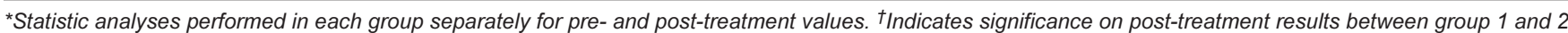

TABLE 3

The percentages of variances by the therapy in groups*

\begin{tabular}{lccr}
\hline & Group 1 (\%) (ursodeoxycholic acid) & Group 2 (\%) (atorvastatin) & P value \\
\hline Aspartate aminotransferase (U/L) & $-0.9 \pm 0.8$ & $-22 \pm 0.5$ & 0.222 \\
Alanine aminotransferase (U/L) & $-26 \pm 0.6$ & $-40 \pm 0.4$ & 0.091 \\
Body mass index & $-0.09 \pm 0.1$ & $-0.1 \pm 0.1$ & 0.850 \\
Liver density (HU) & $+20 \pm 0.9$ & $+35 \pm 0.6$ & 0.201
\end{tabular}

All results are presented as mean \pm SEM. *Percentages of variances were calculated as $100 \times$ (post-treatment value - pretreatment value)/pretreatment value for all parameters.

ferent areas of liver CT slice passing through the porta hepatis has been shown to represent mean fat content of the liver (Figure 1), and it is easy to demonstrate any change in the fat content of the liver with this method. Our observation on histological specimens supported this hypothesis; the degree of steatosis of liver correlates well with its density (Figure 2). Because it is certain that imaging studies cannot distinguish hepatosteatosis from steatohepatitis, liver biopsy must be obtained in all patients to confirm the diagnosis of NASH before therapy.

As a result of response to treatment, liver CT density increases proportionally as the fatty content of the liver decreases. According to our results, such a relationship could be observed only in the atorvastatin group, with no significant change in liver density being observed in the UDCA group after therapy. Although this difference was not statistically significant, it may be suggested that atorvastatin reduces fatty load of the liver while UDCA does not. The first hit of Day and James' "two hits hypothesis" (7) seems to be ameliorated/ eliminated by atorvastatin. UDCA has been demonstrated to diminish cholestasis-mediated overexpression of human lymphocyte antigens class I antigens on hepatocytes and this process makes them less vulnerable to lymphocyte attacks (11). Although these immunological effects appear to be particularly therapeutic in primary biliary cirrhosis, their effects in NASH are unclear.

If normalization of transaminases (final AST below $40 \mathrm{U} / \mathrm{ml}$ and ALT below $43 \mathrm{U} / \mathrm{ml}$ ) is accepted to be a goal or an early end-point, then normalization was achieved in 16 of $27(59 \%)$ patients in the atorvastatin group in contrast to only four of $17(23 \%)$ the patients in the UDCA group $(\mathrm{P}=0.021)$. Laurin et al $(10)$ observed that normalization of transaminases occurred in five of $24(20 \%)$ patients in a UDCA group and two of $16(12 \%)$ patients in a clofibrate group. If Fisher's exact test is performed on their data, no difference exists between the two groups $(\mathrm{P}=0.680)$ and it must therefore be stated that UDCA was not superior to clofibrate in terms of transaminase normalization. Neither this study nor that of Laurin et al (10) was placebo-controlled and it can therefore not definitely be concluded that UDCA is not successful in normalizing transaminases. Nevertheless, it must be said that this effect was not achieved as expected (eg, approximately $20 \%$ of treated cases). Abdelmalek et al (12) published a case report about a patient with NASH in whom transaminases normalized after one year of UDCA treatment. Subsequent withdrawal of the drug resulted in a flare-up of transaminases and reinstitution resulted in a return to normal liver functions again (12). This kind of observation confirms the urgent need for placebo-controlled and randomized trials on this issue.

\section{CONCLUSIONS}

It has recently been reported that statins have many beneficial effects far beyond their lipid lowering properties. They have a positive impact on the vascular system by stabilizing unstable plaques, promoting vascular relaxation and new vessel formation, and can also alleviate renal impairment and insulin resistance. They may also play a role in bone remodelling by stimulating bone formation. These complex effects are accomplished by their unique anti-inflammatory, antioxidative and antithrombotic actions and mediated by small $\mathrm{G}$ proteins of the Ras superfamily, which are involved in many important cellular functions such as proliferation, differentiation, apoptosis and regulation of gene transcription (13). It may therefore be concluded that statins may have the potential to diminish steatosis and/or inflammation in NASH by these mechanisms, and further placebo-controlled studies are needed to confirm these potential benefits. 


\section{REFERENCES}

1. Marchesini G, Brizi M, Bianchi G, et al. Nonalcoholic fatty liver disease: A feature of the metabolic syndrome. Diabetes 2001;50:1844-50.

2. Diehl AM, Poordad F. Nonalcoholic fatty liver disease. In: Feldman M, Friedman LS, Sleisenger MH, eds. Sleisenger \& Fordtran's Gastrointestinal and Liver Disease, 7th edn. Philadelphia: WB Saunders, 2002:1393-401.

3. Bondestam S, Alanen A, Toikkanen S. Correlations of liver echo intensity with cytology and chemical measurements of fat, water and protein content in live burbots (Lota lota). Ultrasound Med Biol 1992;18:75-80.

4. Fishbein MH, Stevens WR. Rapid MRI using a modified Dixon technique: A non-invasive and effective method for detection and monitoring of fatty metamorphosis of the liver. Pediatr Radiol 2001;31:806-9.

5. Brunt EM, Janney CG, Di Bisceglie AM, Neuschwander-Tetri BA, Bacon BR. Nonalcoholic steatohepatitis: A proposal for grading and staging the histological lesions. Am J Gastroenterol 1999;94:2467-74.

6. Kumar KS, Malet PF. Nonalcoholic steatohepatitis. Mayo Clin Proc 2000;75:733-9.
7. Day CP, James OFW. Steatohepatitis: A tale of two "hits"? Gastroenterology 1998;114:842-5.

8. Harrison SA, Kadakia S, Torgerson S, Hayashi P. Vitamin E and vitamin $C$ in the treatment of nonalcoholic steatohepatitis. A prospective, randomized, placebo-controlled clinical trial. A preliminary report. Gastroenterology 2002;122:A669.

9. Mehta K, Van Thiel DH, Shah N, Mobarhan S. Nonalcoholic fatty liver disease: Pathogenesis and the role of antioxidants. Nutr Rev 2002;60:289-93.

10. Laurin J, Lindor KD, Crippin JS, et al. Ursodeoxycholic acid or clofibrate in the treatment of non-alcohol-induced steatohepatitis: A pilot study. Hepatology 1996;23:1464-7.

11. Terasaki S, Nakanuma Y, Ogino H, Unoura M, Kobayashi K. Hepatocellular and biliary expression of HLA antigens in primary biliary cirrhosis before and after ursodeoxycholic acid therapy. Am J Gastroenterol 1991;86:1194-9.

12. Abdelmalek M, Ludwig J, Lindor KD. Two cases from the spectrum of nonalcoholic steatohepatitis. J Clin Gastroenterol 1995;20:127-30.

13. McFarlane SI, Muniyappa R, Francisco R, Sowers JR. Pleiotropic effects of statins: Lipid reduction and beyond. J Clin Endocrinol Metab 2002;87:1451-8. 


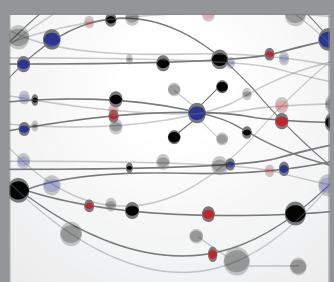

The Scientific World Journal
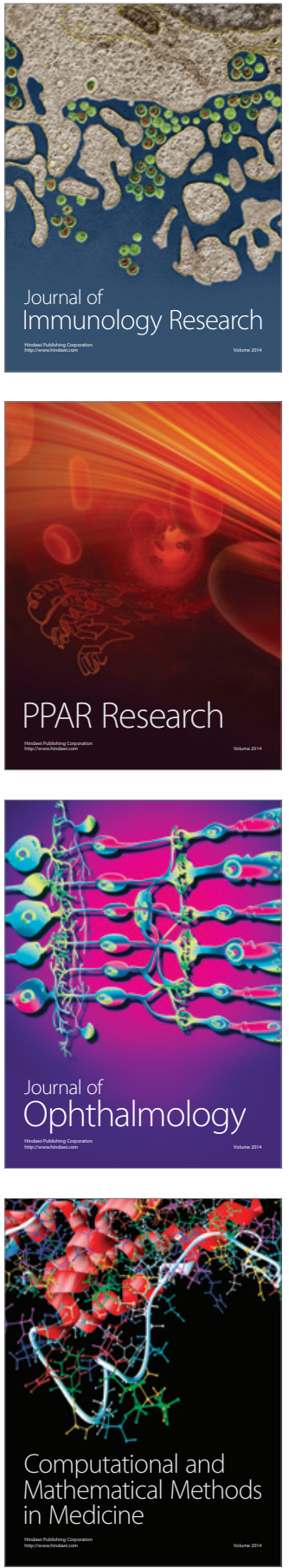

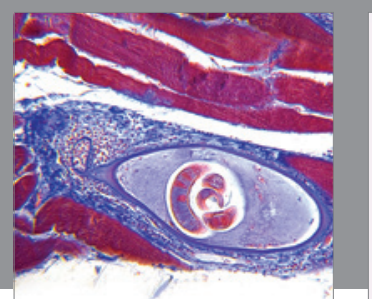

Gastroenterology Research and Practice

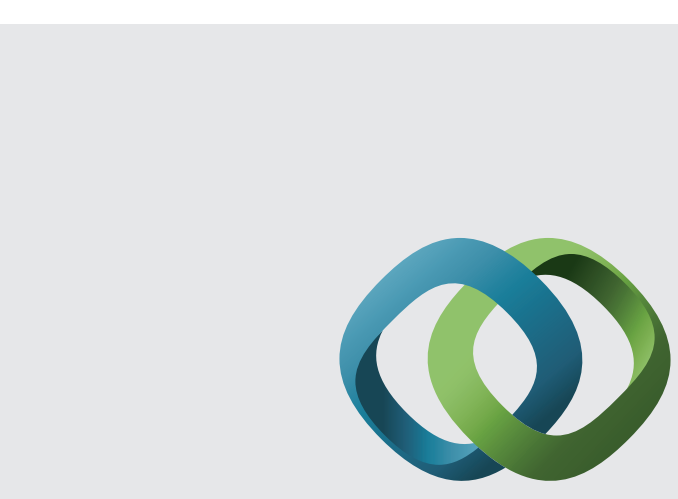

\section{Hindawi}

Submit your manuscripts at

http://www.hindawi.com
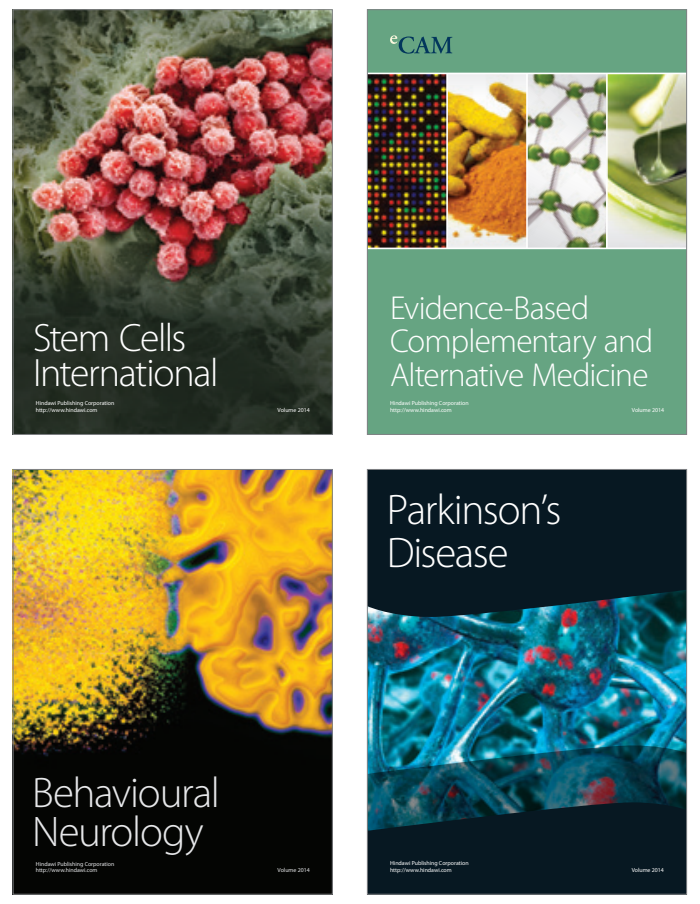
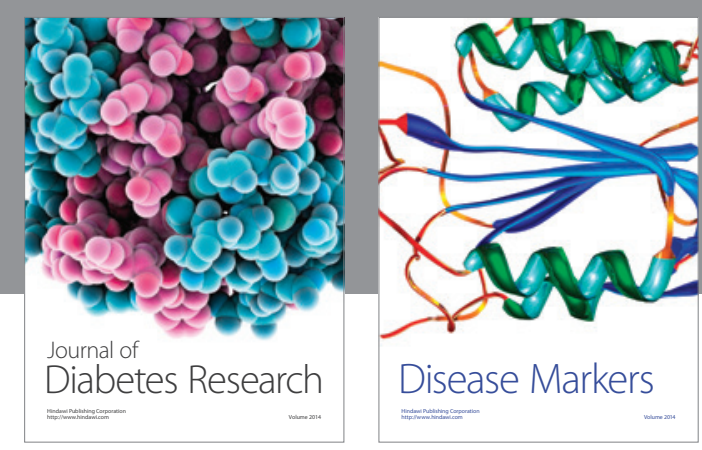

Disease Markers
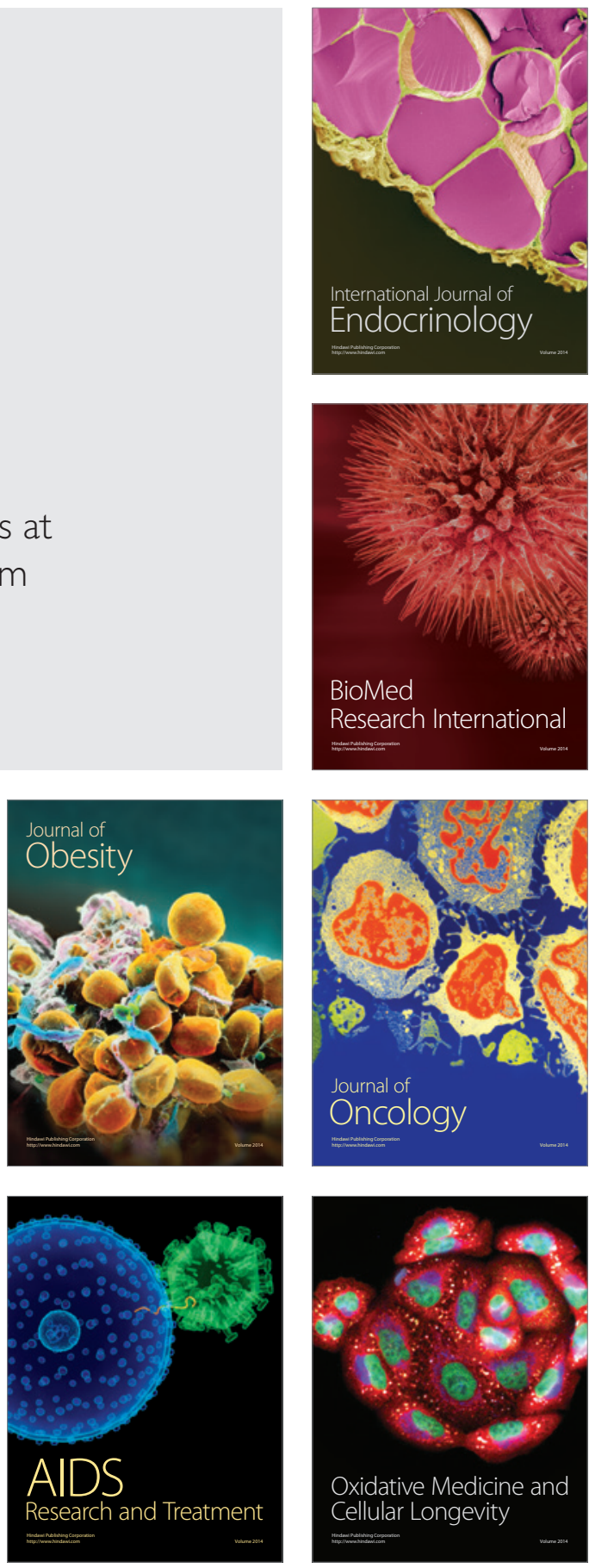